\title{
Unrecognized human immunodeficiency virus infection and risk factors among elderly medical patients at the Korle Bu teaching hospital, Accra, Ghana
}

Andrew A. Adjei ${ }^{1,4^{*}}$, Seth Agyemang ${ }^{2}$, Francis D. Krampa ${ }^{3}$, Mubarak Abdul-Rahman $^{4}$, Francis Ofei ${ }^{5}$, Margaret Lartey ${ }^{5}$, Theophilus K. Adikü ${ }^{3}$, Richard K. Gyasi ${ }^{4}$ and Yao Tettey ${ }^{4}$

\begin{abstract}
Background: The human immunodeficiency virus (HIV) infection usually infects persons in the reproductive age group (15-49 years), but elderly people are also susceptible. Many people in sub-Saharan Africa including Ghana believe that elderly people are not at risk for HIV. Despite numerous reports of the high prevalence of HIV infection among the elderly worldwide, there are no from Ghana. This work determined the sero-prevalence of HIV infection and risk factors for its transmission among 1,100 hospitalized elderly people at the Korle Bu Teaching Hospital (KBTH), Accra, Ghana.
\end{abstract}

Methods: Subjects voluntarily completed a risk-factor questionnaire and provided a blood specimen for HIV testing. Results: Of the study participants, 440 were male (mean age: $64 \pm 10.55$ years), and 660 were female (mean age: $63 \pm 9.51$ years). The overall HIV-1 sero-prevalence among the subjects was $4.18 \%(n=46)$. On multivariate analysis, there was no statistical significance between the socio-demographics or risk factors and the HIV status of the participants.

Conclusion: The results suggest high prevalence of HIV-1 among hospitalized elderly people at KBTH, recommending the need to include the elderly in HIV/AIDS testing, prevention, and control programmes.

Trial registration: Trial registration number: MS-Et/M.9 - p4.10/2012-2013. Registered: 10th April, 2013.

Keywords: HIV, Hospital, Admission, Elderly, Ghana

Abbreviations: AIDS, Acquired Immune Deficiency Syndrome; HIV, The human immunodeficiency virus; KBTH, Korle Bu Teaching Hospital; NACP, National AIDS Control Programme; SME, Surgical/Medical Emergency; UGSMD, University of Ghana School of Medicine and Dentistry

\section{Background}

Human immunodeficiency virus (HIV) infection exists worldwide with particularly high rates of infection in sub-Saharan Africa [1-3]. Of the 1.8 million HIV/AIDS related-deaths recorded worldwide in 2010, 1.2 million were from sub-Saharan Africa [4]. The burden of HIV/

\footnotetext{
*Correspondence: aaadjei@ug.edu.gh; andrewanthonyadjei@yahoo.com ${ }^{1}$ Office of Research, Innovation and Development, University of Ghana, Legon, Accra, Ghana

${ }^{4}$ Department of Pathology, School of Biomedical and Allied Health Sciences, College of Health Sciences, University of Ghana, Accra, Ghana

Full list of author information is available at the end of the article
}

AIDS disease is higher in young people (15-49 years old) than in older people ( $>50$ years old) $[4,5]$ and as a result, most of the known epidemiological and clinical features of HIV/AIDS were defined and continued to be defined using younger populations [4-7]. Subsequently, most of the HIV/AIDS prevention efforts largely target young persons and people in reproductive age group. Little is known about the attitudes towards HIV and awareness of prevention, testing and treatment among older people in sub-Saharan Africa. 
Ghana, one of the growing economies in sub-Saharan Africa, has been experiencing the HIV/AIDS epidemic since the first Ghanaian tested positive for HIV-1 antibodies in 1986 [8]. The prevalence of HIV infection in Ghana has rapidly decreased over the past years and the current prevalence rate is $1.37 \%$ [9]. Sentinel studies conducted by the National AIDS control Programme (NACP) included most sub-populations thought to be at high-risk for HIV and sexually transmitted infections (STIs), but excluded older people ( $>50$ years old) [9]. Recent reports indicate that the diagnosis of HIV infection is occurring with increasing frequency in older people [10-12]. The Centers for Disease Control and Prevention (CDC) reported that HIV/AIDS cases among American adults over 50 years of age quintupled during the last decade [7]. Similar results were reported in France [13], Australia, Canada, United Kingdom [14], Brazil [13], Egypt [15], Tanzania [16], Kenya [17], and Uganda [10, 14].

Anecdotal reports from the Department of Medicine and Therapeutics, Korle Bu Teaching Hospital (KBTH), Accra, Ghana, indicate a rise of older people ( $>50$ years old) on admission at both the Surgical/Medical Emergency (SME) Ward and the Medical Wards, Department of Medicine and Therapeutics, KBTH; and that, age- related illnesses were the leading cause of death among the elderly ( $>60$ years old) on admission. Although several studies have indicated that older patients with HIV infection present with non-specific problems or signs and symptoms that mimic age-related illnesses [18], the testing and diagnosis of HIV-related immune-suppression were not done, unrecognized or overlooked among the patients on admission in both wards. Consequently, the sero-prevalence of HIV and/or HIV/AIDS-related death among the elderly patients was not included in the report.

Several reports are available globally on the seroprevalence of HIV among the elderly patients on admission in hospitals $[15,16,19,20]$ and also in the general population [17, 21-23]. However, in Ghana, HIV infection among older people has largely been ignored over the years with little or no information on the seroprevalence and HIV-related knowledge and attitudes among older people. Some of the factors that may explain the lack of interest or late diagnosis of HIV infection in the older people may include less common routine screening, lack of appreciation of physicians and/or clinicians of HIV infections in the elderly, and the lack of information on the contribution of HIV infection to the morbidity in older people. Additionally, there is confusion between symptoms of opportunistic infections and those of frequent co-morbid conditions associated with ageing. In Ghana, most HIV/AIDS health policies and programmes target the traditionally vulnerable (substance users, patients seen at STI clinics and incarcerated persons), women and children, without any focus on elderly populations. Similarly, research studies typically exclude older participants [9]. This work therefore determined the sero-prevalence of HIV infection among hospitalized elderly patients at KBTH. We also examined the association of HIV with various suggested risk factors for its transmission.

\section{Methods}

\section{Study site description}

The study is a hospital-based, cross sectional study carried out between the months of December 2012 to January 2014 among elderly patients on admission at the Surgical Medical Emergency (SME) and Medical Wards at the KBTH. Ghana is divided into ten (10) administrative regions, subdivided into a total of 216 districts or municipalities. $\mathrm{KBTH}$, situated in Accra is the leading tertiary hospital and the major referral centre in Ghana. It also serves as the teaching hospital of the University of Ghana School of Medicine and Dentistry (UGSMD), Accra, Ghana. Both the KBTH and the UGSMD are situated in the Greater Accra Region. The SME/Medical Wards are its biggest tertiary care centres and more than $40 \%$ of the total cases involving older people seen in the country are processed through the Department of Medicine and Therapeutics.

\section{Study population}

Subjects for this study included both male and female patients aged 50 years and older admitted in both SME and the Medical Wards. Patients originated from various social and ethnic groups as well as geographically distinct areas from the vast territory of all the 10 regions of Ghana. Patients who were not admitted to these wards, whose HIV/AIDS status were known or were critically ill were not included in the study. The study was presented to the entire population of each ward at dedicated research meetings. The patients were informed that the study was confidential and that the information provided would not affect their admission or treatment status. The objective of the study was clearly explained to all potential participants in any local Ghanaian language that they best understood, after which a written informed consent was obtained and kept at the principal investigator's office. A total of 1,100 patients consented to participate in the study.

\section{Questionnaire}

All 1,100 consenting patients completed an interviewbased questionnaire assessing socio-demographic characteristics, including age, sexual orientation, drug and alcohol histories, knowledge and history of HIV/AIDS, STIs, and a risk factor profile for the infection under investigation. The interviews were conducted by trained nurses. 


\section{Sample collection and serological analysis}

Blood samples (approximately $5 \mathrm{ml}$ ) were collected from each of the 1,100 participants into EDTA tubes. Samples were centrifuged ( $2500 \mathrm{rpm}$ for $10 \mathrm{~min}$ ) and the separated plasma kept at $-80^{\circ} \mathrm{C}$ until analysed. Plasma were screened for HIV (1 \& 2) antibodies/antigens with a COBAS e411 immunoassay (ROCHE Diagnostics, Manheim, Germany). Reactive specimens were re-tested with reverse transcription polymerase chain reaction, RT-PCR (ROCHE Diagnostics) at the Immunology and Cell Biology Department, Central Laboratory, $\mathrm{KBTH}$, in accordance with the respective manufacturer's instructions.

\section{Data analysis}

The Statistical Analysis Software (SAS Institute, Cary, $\mathrm{NC}$, USA) version 9.1 was used to complete all data analyses. For each generally accepted risk factor for HIV infection, the odds ratio (OR) and the $95 \%$ confidence interval $(95 \% \mathrm{CI})$ were calculated to assess associations with socio-demographic and behavioural variables in univariate analysis. A $P$-value of $<0.05$ was considered significant and the Fisher's exact test was used in estimating significance in relatively small frequencies. Independent associations were evaluated by calculating the adjusted OR using multivariate analysis for the sociodemographic variables found to be significant in the univariate analysis.

\section{Ethical approval}

The Ethical and Protocol Review Committee of the University of Ghana, College of Health Sciences approved the study prior to enrolment.

\section{Results}

\section{Patient distribution, age and clinical conditions}

A total of 1,100 people participated in the study. Of the participants, $440(40 \%)$ were male (mean age: $64 \pm 10.55$ years), and 660 (60\%) were female (mean age: $63 \pm 9.51$ years). The participation for the study at the two sites ranged from $39.5 \%$ (SME) to $60.5 \%$ (Medical Block). All 1,100 participants completed interviews and blood testing. All the consenting elderly people were Ghanaians and data from male and female elderly people were combined.

Of the 1,100 patients, $75.18 \%$ (827 out of 1,100$)$ had been admitted at the hospital for less than 4 weeks while $24.82 \%$ (273 out of 1,100 ) had been in hospital for more than 4 weeks. The most common cause for their admission was hypertension (blood pressure $\geq 140 / 90 \mathrm{mmHg})$ in $51 \%(n=561)$, diabetes in $37.55 \%(n=413)$ followed by cancer $5.64 \%(n=62)$. Other diagnoses accounted for $5.18 \%$ of the study population. Eighty percent of the participants had never been tested for HIV.

\section{Prevalence of HIV among study patients}

Forty-six (4.18\%) participants tested sero-positive for HIV-1 after COBAS e411 immunoassay and RT-PCR. None tested positive for HIV-2. The sero-prevalence of HIV-1 was highest in participants aged $>75$ years and lowest among participants aged 61-75 years (Table 1a).

Table 1 shows the ORs and corresponding $95 \%$ CIs according to age, gender and HIV sero-positivity. Of the participants who tested positive for HIV-1, there was no significant difference by gender; $58.70 \%(n=27$ out of 46$)$ were female, while $41.30 \%(n=19$ out of 46$)$ were male. The younger group (ages 50-60) had higher rates of HIV sero-positivity ( $52.17 \% ; n=24$ out of 46$)$ compared to elderly people aged $61-75$ years $(23.91 \% ; n=11$ out of 46) and those aged $\geq 76$ years ( $23.91 \% ; n=11$ out of 46$)$ ) but the differences were not statistically significant.

Table 2 shows ORs and the corresponding $95 \%$ CIs for demographic characteristics and HIV sero-positivity among the elderly people on admission. Married elderly people accounting for $86.91 \%$ of the study participants had higher proportions of HIV sero-positivity compared with those who w not married. There were no statistically significant differences in demographics between the positives and negatives

Table 3 shows the ORs and corresponding $95 \% \mathrm{CI}$ according to behavioural characteristics and HIV seropositivity. There were no statistically significant differences in behavioural characteristics between the positives and negatives.

Table 4 shows HIV awareness and knowledge in prevention and transmission among the study participants. The majority of respondents had heard of HIV and were aware of STIs. Only $26.10 \%$ of the participants knew that correct and consistent use of condom could protect people from getting HIV, while $60.9 \%$ of participants did not know that a person can protect himself/herself through abstinence. Seventy-three percent of participants thought that healthy-looking individuals could not be infected with HIV.

Table 1 ORs and the corresponding $95 \%$ Cls of age and gender for HIV sero-positivity among the study patients

\begin{tabular}{|c|c|c|c|c|c|}
\hline \multirow{3}{*}{$\begin{array}{l}N \\
{[1,100]}\end{array}$} & \multicolumn{2}{|c|}{ HIV Status } & \multirow[t]{3}{*}{ OR } & \multirow[t]{3}{*}{$95 \% \mathrm{Cl}$} & \multirow[t]{3}{*}{$p$-value } \\
\hline & Pos & Neg & & & \\
\hline & (46) & (1054) & & & \\
\hline
\end{tabular}

\begin{tabular}{lllllll}
\hline Age & & & & & & \\
$50-60$ & 498 & 24 & 474 & a & - & - \\
$61-75$ & 459 & 11 & 448 & 0.49 & $0.24-1.00$ & 0.03 \\
$>75$ & 143 & 11 & 132 & 1.65 & $0.79-3.45$ & 0.13 \\
Gender & & & & & & \\
Male & 440 & 19 & 421 & 1.06 & $0.5-1.93$ & 0.48 \\
Female & 660 & 27 & 633 & a & - & - \\
\hline
\end{tabular}

${ }^{a}$ : references for calculations of $\mathrm{OR}$ 
Table 2 ORs and the corresponding $95 \%$ Cls demographic factors and HIV sero-positivity among the study patients

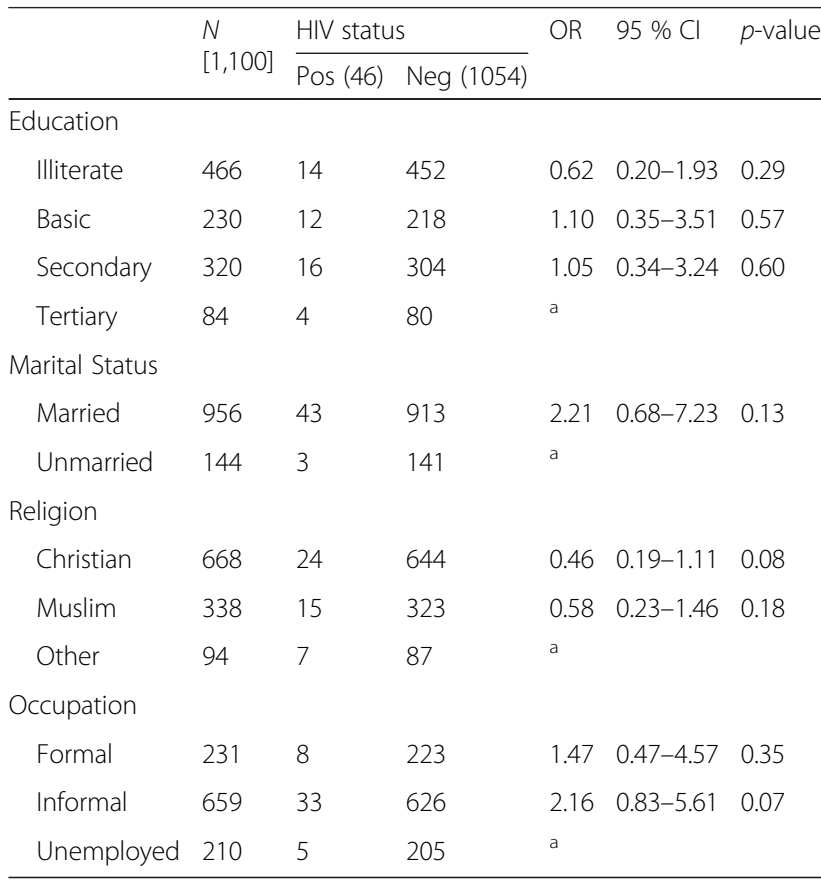

a: references for calculations of $\mathrm{OR}$

\section{Discussion}

To our knowledge, there are no studies that have assessed the prevalence rates of HIV and its impact on the health and well-being of the elderly people in the Ghanaian setting despite the increasing growth of the elderly population and the significant role(s) they play in both social and family settings.

Undocumented reports indicating a rise of older people ( $>60$ years old) on admission at both the SME Ward and the Medical Wards, Department of Medicine and Therapeutics, KBTH among the elderly raises a major public health concern in the era of global HIV/ AIDS pandemic. Notably, HIV/AIDS was not included in the cause(s) of death among the elderly emphasizing the perception that the elderly are at a little or no risk of HIV infection.

Our results of $4.18 \%$ sero-prevalence rate among the elderly people on admission at the Wards suggest that HIV may pose a significant problem and that the detection and diagnosis of HIV among elderly people may remain unrecognized during their lives. The reason(s) for the failure of "early" detection of HIV among the elderly cannot be discerned from our study. However, one of the reasons may be the misconception of the association of the elderly with HIV. In the Ghanaian traditional society, the elderly are held in high esteem because of the leading and significant roles they play as heads of families, "fountain(s)" of wisdom, and roles in conflict resolutions. As such, many Ghanaians
Table 3 ORs and corresponding $95 \%$ Cl of HIV status according to behavioural character of the elderly hospitalized patients

\begin{tabular}{|c|c|c|c|c|c|c|}
\hline & \multirow{2}{*}{$\begin{array}{l}N \\
{[1,100]}\end{array}$} & \multicolumn{2}{|c|}{ HIV Status } & \multirow[t]{2}{*}{ OR } & \multirow[t]{2}{*}{$95 \% \mathrm{Cl}$} & \multirow[t]{2}{*}{$p$-value } \\
\hline & & Pos (46) & Neg (1054) & & & \\
\hline \multicolumn{7}{|c|}{ Condom use } \\
\hline No & 1053 & 43 & 1010 & 0.67 & $0.20-2.23$ & 0.35 \\
\hline Yes & 47 & 3 & 44 & a & & \\
\hline \multicolumn{7}{|c|}{ Concurrent sex partners } \\
\hline No & 702 & 27 & 674 & a & & \\
\hline Yes & 398 & 19 & 379 & 1.25 & $0.69-2.28$ & 0.28 \\
\hline \multicolumn{7}{|c|}{ Drug use } \\
\hline No & 1088 & 46 & 1042 & a & & \\
\hline Yes & 12 & 0 & 12 & & - & 0.60 \\
\hline \multicolumn{7}{|c|}{ Alcohol use } \\
\hline No & 663 & 28 & 635 & a & & \\
\hline Yes & 437 & 18 & 419 & 0.97 & $0.53-1.78$ & 0.53 \\
\hline \multicolumn{7}{|c|}{ Smoking history } \\
\hline No & 979 & 42 & 937 & a & & \\
\hline Yes & 121 & 4 & 117 & 0.76 & $0.27-2.17$ & 0.42 \\
\hline \multicolumn{7}{|c|}{ Chewing tobacco } \\
\hline No & 986 & 39 & 947 & a & & \\
\hline Yes & 114 & 7 & 107 & 1.59 & $0.69-3.64$ & 0.19 \\
\hline \multicolumn{7}{|c|}{ History of STI } \\
\hline No & 1095 & 46 & 1049 & a & & \\
\hline Yes & 5 & 0 & 5 & - & - & 0.81 \\
\hline \multicolumn{7}{|c|}{ Symptoms of STI } \\
\hline No & 167 & 6 & 161 & a & & \\
\hline Yes & 933 & 40 & 893 & 1.20 & $0.50-2.88$ & 0.44 \\
\hline \multicolumn{7}{|c|}{ Payment for sex } \\
\hline No & 985 & 40 & 945 & a & & \\
\hline Yes & 115 & 6 & 109 & 1.30 & $0.54-3.14$ & 0.35 \\
\hline \multicolumn{7}{|c|}{ Tattoos } \\
\hline No & 633 & 28 & 605 & a & & \\
\hline Yes & 467 & 18 & 449 & 0.87 & $0.47-1.59$ & 0.38 \\
\hline \multicolumn{7}{|c|}{ Blood transfusion } \\
\hline No & 568 & 27 & 541 & a & & \\
\hline Yes & 532 & 19 & 513 & 0.74 & $0.41-1.35$ & 0.20 \\
\hline
\end{tabular}

${ }^{a}$ : references for calculations of $\mathrm{OR}$

mistakenly believe that elderly people are not at risk and do not engage in risky behaviours. Another reason may be the failure of clinicians and/or physicians to document factors, such as homosexuality, previous history of drug use, condom use, and multiple sexual partners that are associated with HIV in elderly people. Although only three study participants identified as homosexual, two of them tested positive for HIV-1, suggesting that known HIV risk factors are 
Table 4 HIV awareness among patients

\begin{tabular}{llr}
\hline HIV awareness & \multicolumn{2}{c}{ Response (\%) } \\
\cline { 2 - 3 } & Yes & No \\
\hline Have you heard of HIV/AIDS? & 93.7 & 6.3 \\
Are you aware of STIs? & 87.7 & 12.3 \\
Can correct use of condoms prevent HIV? & 26.1 & 73.9 \\
Can HIV be acquired through food? & 25.8 & 74.2 \\
Can HIV be acquired through handshakes/touch? & 94.3 & 5.7 \\
Can HIV be acquired through contaminated needles? & 66.8 & 33.2 \\
Can HIV be acquired through contaminated blood? & 73.5 & 26.5 \\
Can a person protect himself from HIV by abstaining? & 39.1 & 60.9 \\
Can healthy individual be infected with HIV? & 37.0 & 63.0 \\
Is there Medication to cure HIV? & 42.3 & 57.7 \\
Can pregnant woman pass HIV to unborn child? & 21.4 & 78.6 \\
\hline
\end{tabular}

also relevant in an elderly population. In addition to just not considering HIV in older patients, it is also possible that clinicians attribute symptoms of opportunistic infections to common aging-associated co-morbid conditions. Further studies are needed to better define the sero-prevalence of HIV in Ghanaians aged 50 and older.

The participants in this study demonstrated a significant lack of knowledge about HIV/AIDS and STI acquisition and transmission as well as ignorance of their own HIV status and risk. These findings should prompt further efforts to educate older Ghanaians about sexual health and to increase awareness among health care providers that HIV/AIDS in the elderly population is a salient and underappreciated issue.

The overall sero-prevalence of HIV among the elderly patients on admission at KBTH (4.18 \%) was higher than the sero-prevalence in the general population (1.37\%) and that of similar studies in Cameroon (2.6\%) [12]. The result is comparable to studies conducted in northwestern Ethiopia (5 \%) [21], but lower than the reported sero-prevalence of HIV in elderly individuals in Tanzania (15\%) [20]. The sero-prevalence of HIV infection among the elderly people admitted at both SME/Medical Wards, KBTH suggests that HIV is likely prevalent in the elderly inpatient populations in other districts. Further studies to be done among the elderly inpatient populations in other health facilities in Ghana to measure the sero-prevalence and define the risk factors associated with HIV infection in this valued group.

The risk of HIV did not correlate with increasing age, however, elderly people aged $>75$ years on admission tended to have a higher proportion of HIV infection (Table 1). Similar findings were noted in a study conducted by Mtei \& Pallangyo, 2001 in Muhimbili Medical Center, Dar es Salaam, Tanzania. The reason(s) for this disparity cannot be discerned from this study and hence, there is the need for further studies to be done to define the impact of HIV on the health and well-being of elderly people in the population.

Another finding of interest reported herein in this study is that a greater number of sero-positive participants $(n=33$ out of 46$)$ were in the informal employment sector. They consisted mainly traders who travelled long distances for several weeks to engage in trading activities. A higher HIV sero-positivity in traders may be attributed to separation from partners and family, peer influence, alcohol and drug use, low perceived vulnerability to HIV infection and freedom from social norms. The higher sero-prevalence among this group, especially traders who travel long distances and spend several weeks away from home is suggests that the traders may constitute a bridge or core population in the spread of HIV and other STIs which would be consistent with existing literature [24-26]. This finding presents another opportunity for further research to investigate the sero-prevalence of HIV in elderly traders and any correlation with geographic spread of the infection.

As documented in other studies, condom use was rare in this population of elderly inpatients [27-29]. Of the 46 participants who tested positive for HIV, 43 reported no history of condom use during sexual intercourse.

There are many limitations to this study. The small sample size, inability to collect information on sexual practices prior to admission, likely under-reporting of sexual activity, alcohol use and other risk behaviours as a result of the face-to-face interview, failure to explore or define the effects of separation from families and cultural factors in predicting risk behaviours of elderly people, and the inability to determine CD4 counts and viral loads all limit the interpretation and generalizability of the data. Further studies need to be done to verify the results presented herein and also determine the exact prevalence of HIV among the elderly in the country.

\section{Conclusion}

In conclusion, the prevalence of HIV (4.18 \%) among the elderly people on admission at both SME and Medical Wards at the KBTH is higher than the national prevalence $(1.37 \%)$. National HIV prevalence data for elderly Ghanaians is not currently available but should be collected. Based on these data, there should be considerations to include the elderly in HIV/AIDS prevention and control programmes that provide general HIV and STI education.

\section{Acknowledgments}

Our sincere appreciation to the nurses and healthcare givers of the Department of Medicine and Therapeutics, KBTH. We are also grateful to all the all the participants in the study.

\section{Funding}

We received no funding for this research. 


\section{Availability of data and material}

The datasets are available from the corresponding author upon request.

\section{Authors' contributions}

AAA designed the study, interpreted results and drafted the manuscript. SA and FDK carried out the immunoassays and performed statistical analysis. MA, ML and FO helped to draft the manuscript. TKA, RKG and YT critically revised the manuscript. All authors read and approved the final manuscript.

\section{Competing interests}

The authors declare that they have no competing interests.

\section{Consent for publication}

Not applicable.

\section{Ethics approval and consent to participate}

This study was approved by the University of Ghana, College of Health Sciences' Ethical and Protocol Review Committee on 10th April, 2013 (Reference Number: MS-Et/M.9 - p4.10/2012-2013).

Written informed consent was obtained from participants before their enrolment into the study.

\section{Author details}

${ }^{1}$ Office of Research, Innovation and Development, University of Ghana, Legon, Accra, Ghana. ${ }^{2}$ Immunology Department, Central Laboratories, Korle Bu Teaching Hospital, Accra, Ghana. ${ }^{3}$ Department of Microbiology, School of Biomedical and Allied Health Sciences, College of Health Sciences, University of Ghana, Accra, Ghana. ${ }^{4}$ Department of Pathology, School of Biomedical and Allied Health Sciences, College of Health Sciences, University of Ghana, Accra, Ghana. ${ }^{5}$ Department of Medicine and Therapeutics, University of Ghana School of Medicine and Dentistry, Accra, Ghana.

\section{Received: 30 April 2016 Accepted: 23 August 2016}

\section{Published online: 02 September 2016}

\section{References}

1. Parker R. The global HIV/AIDS pandemic, structural inequalities and the politics of international health. Am J Public HIth. 2002;92:343-6.

2. Joint United Nations Programme on HIV and AIDS. AIDS at 30: Nations at the Crossroads. Geneva, Switzerland: UNAIDS. 2011 a.

3. World Health Organisation. Global HIV/AIDS response, Geneva. Progress Report 2011. Available from: http://www.who.int/hiv/pub/progress_ report2011/en/. Accessed 9 April 2014.

4. Joint United Nations Programme on HIV/AIDS and World Health Organization. AIDS epidemic update. December 2003.

5. Joint United Nations Programme on HIV/AIDS. Global HIV/AIDS Response: Epidemic Update and Health Sector Progress Towards Universal AccessProgress Report. Geneva: UNAIDS; $2011 \mathrm{~b}$

6. Deeks SG, Lewin SR, Havlir DV. The end of AIDS: HIV infection as a chronic disease. Lancet. 2013;382(9903):1525-33.

7. Centers for Disease Control Prevention. AIDS cases in adolescents and adults by age-United States, 1992-2000. HIV/AIDS Surveill Suppl Rep. 2003; 1-24.

8. Neequaye AR, Mingle JA, Neequaye JE, Agadzi VK, Nettey V, Osei-Kwasi M, et al. A report of human immuno-deficiency virus (HIV) infection in Ghana up to December 1986. Ghana Med J. 1987;21:7-11

9. National AIDS/STI Control Programme. HIV Sentinel Surveillance Report, Ministry of health, Ghana Health Service. 2013.

10. Nyirenda M, Newell ML, Mugisha J, Mutevedzi PC, Seeley J, Scholten F, Kowal P. Health, wellbeing, and disability among older people infected or affected by HIV in Uganda and South Africa. Global health action. 2013;6: 19201. doi:10.3402/gha.v6i0.19201

11. Brooks JT, Buchacz K, Gebo KA, Mermin J. HIV infection and older Americans: the public health perspective. Am J Public Health. 2012; 102(8):1516-26

12. Negin J, Cumming RG. HIV infection in older adults in sub-Saharan Africa: extrapolating prevalence from existing data. Bull World Health Organ. 2010; 88(11):847-53.

13. Lacerda HR, Kitner D. Mortality of the elderly is still exceedingly high at diagnosis of AIDS despite favourable outcomes after highly active antiretroviral therapy in Recife Brazil. Intern J STD/AIDS. 2008;19:450-4
14. Nguyen N, Holodoniy M. HIV infection in the elderly. Clin Interven Aging. 2008:3:253-472.

15. El-Sadr W, Gettler J. Unrecognised human immunodeficiency virus infection in the elderly. Arch Intern Med. 1995;155:184-6.

16. Nyigo V, Kilale A, Kilima S, Shayo EH, Senkoro KP, Mshana J, Mushi AK, Matemba L, Massaga J. Magnitude of HIV infection among older people in Mufindi and Babati districts of the Tanzania mainland. HIV/AIDS. 2014;6:75.

17. Kyobutungi C, Ezeh AC, Zulu E, et al. HIV/AIDS and the health of older people in the slums of Nairobi, Kenya: results from a cross-sectional survey. BMC Public HIth. 2009;153.

18. Grabar S, Weiss L, Costagliola D. HIV infection in older patients in the HAART era. J Antimicrob Chemother. 2006;57:4-7.

19. Gaeta TJ, LaPolla C, Melendez E. AIDS in the elderly: New York City Vital Statistics. J Emerg Med. 1996;14:19-23.

20. Mtei LN, Pallangyo P. HIV infection in elderly medical patients. East Afr Med J. 2001;78(3):144-7.

21. Kassau A, Mekonnen A, Bekele A, et al. HIV and syphilis infections among elderly people in Northwestern Ethiopia. Jpn J Infect Dis. 2004;57:264-7.

22. AIDS Info Net. Fact Sheet 616. Older people and HIV. 2013. Available from: http: //www.aidsinfonet.org/fact_sheets/view/616. Accessed 12 Feb 2014.

23. Nyigo V, Kilale A, Kilima S, et al. Magnitude of HIV infection among older people in Mufindi and Babati districts of the Tanzania mainland. HIV/AIDS Research and Palliative Care. 2014;6:75-9.

24. Brummer D. Labour migration and HIV/AIDS in Southern Africa. International Organisation for Migration Regional Office for Southern Africa. 2002.

25. Anderson A, Qingsi Z, Hua X, et al. China's floating population and the potential for HIV transmission. AIDS CARE. 2003;15:177-85.

26. Lurie M, William B, Suma $K$, et al. The impact of migration on HIV-transmission in South Africa: A study of migrant and nonmigrant men and their partners. Sex Transm Dis. 2003;30:149-56.

27. World Health Organization. Effectiveness of male latex condoms in protecting against pregnancy and sexually transmitted infections, Geneva. Fact Sheet No. 243, June 2000

28. Foss AM, Watts $\mathrm{CH}$, Vickerman $\mathrm{P}$, et al. Condoms and prevention of HIV BMJ. 2004:329(7459):185-6.

29. Holmes KK, Levine R, Weaver M. Effectiveness of condoms in preventing sexually transmitted infections. Bull World Health Organ. 2004:82(6):454-61.

\section{Submit your next manuscript to BioMed Central and we will help you at every step:}

- We accept pre-submission inquiries

- Our selector tool helps you to find the most relevant journal

- We provide round the clock customer support

- Convenient online submission

- Thorough peer review

- Inclusion in PubMed and all major indexing services

- Maximum visibility for your research

Submit your manuscript at www.biomedcentral.com/submit
Biomed Central 